\title{
A generalização da precariedade: trabalho e classes no capitalismo contemporâneo*
}

Fabrício Maciel**

Resumo: Este artigo explora a hipótese de que a generalização da precariedade é a principal marca do capitalismo contemporâneo. Compreende-se como precariedade o fenômeno contemporâneo de padecimento das relações e das condições de trabalho. O texto é dividido em quatro partes. Primeiro, verifica a condição de globalidade alcançada atualmente pela sociedade do trabalho e das classes. Na sequência, investiga como o conhecimento especializado, científico e tecnológico se torna ao mesmo tempo uma nova força produtiva central e uma ideologia do capitalismo contemporâneo. Depois, procura mostrar como a relação entre trabalho e classe conforma a principal questão social atual e por que ela precisa ser tematizada. Por fim, busca-se uma síntese de como se estrutura atualmente o fenômeno da generalização da precariedade. Com isso, o artigo sugere uma nova tematização da relação entre trabalho e classe, enquanto conceitos e realidades empíricas, no capitalismo contemporâneo.

Palavras-chave: Precariedade. Trabalho. Classes sociais. Capitalismo. Conhecimento.

\section{The generalization of precariousness: work and classes in the contemporary capitalism}

Abstract: This paper examines the hypothesis that the generalization of precariousness is the main characteristic of contemporary capitalism. It is understood that precariousness is the contemporary process of suffering of the relations and conditions of work. The text is divided into four parts. First, it is verified the global condition reached by work and class society nowadays. Next, it investigates how specialized, scientific and technological knowledge turns into a new central productive force and an ideology of contemporary capitalism at the same time. Then, the paper intends to show what the main social question of the globalized work society is and why it needs to be object of study. Lastly, we tried to synthesize how the phenomenon of the generalization of precariousness structures today. Thus, the article suggests a new approach of the relation between work and class as concepts and empirical realities of contemporary capitalism.

Keywords: Precariousness. Work. Social classes. Capitalism. Knowledge.

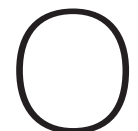

tema da precariedade das relações e das condições de trabalho conforma um dos mais urgentes debates das ciências sociais contemporâneas, tanto no cenário global como no brasileiro. No primeiro plano, a obra de Robert Castel, na França, destaca-se por sua tematização da "institucionalização do preca-

\section{* Este artigo é resultado de minha estadia de pós-doutorado na Universidade Humboldt, de Berlim, Alemanha, entre 2014 e 2015. Agradeço a Coordenação de Aperfeiçoamento de Pessoal de Nível Superior (Capes) e ao Deutscher Akademischer Austauschdienst (Daad) pela concessão de uma bolsa no escopo de um projeto no âmbito do Programa Brasil-Alemanha (Probral), sem a qual eu não teria realizado este trabalho.}

Agradeço aos pareceristas anônimos da Sociedade e Estado que prestaram valiosas contribuições à versão final deste texto.

** Fabrício Maciel
realizou o pós-
doutorado em
sociologia na
Universidade
Humboldt de
Berlim; é doutor
em ciências sociais
oela Universidade
Federal de Juiz
de Fora (UFJF).
Professor adjunto
na Universidade
Federal Fluminense

** Fabrício Maciel realizou o pósdoutorado em Humboldt de Berlim; é doutor em ciências sociais oela Universidade Federal Fluminense 
(UFF), Campos dos Goytacazes, Rio de Janeiro, Brasil, e professor permanente do Programa de Pós Graduação em Sociologia Política da Universidade Estadual do Norte Fluminense Darcy Ribeiro (UENF), Rio de Janeiro, Brasil. Orcid no: 00000003-4553-6223. <macielfabricio@ gmail.com>. riado" (Castel, 2011), que ele articulará em sua tentativa de compreender os novos processos de exclusão social no cenário francês e europeu, através do que chama de "desfiliação social", ou seja, o fenômeno no qual o mercado expulsa um número cada vez maior de trabalhadores de seus postos seguros de trabalho, sem criar novas condições para sua reinserção, imergindo-os permanentemente na condição de "sobrantes" (Castel, 1998; 2011).

Na Alemanha, a obra tardia de Ulrich Beck debruça-se atentamente sobre a preocupação com a precarização do trabalho na Europa, especialmente depois de, nos anos de 1990, o sociólogo alemão ter visitado o Brasil e ficado impressionado com aquilo que ele veio a definir como o futuro do padrão do trabalho na Europa, ou seja, a desregulação como regra, que ficará conhecida com sua famosa tese sobre a "brasilização do Ocidente" (Beck, 2007). Para Beck, o elo entre Estado, economia e sociedade civil, essencial para a democracia, é rompido quando não há mais a garantia de emprego para a grande maioria dos membros de uma sociedade, privilégio este vivido por países como Alemanha, França e Inglaterra, no período dourado do welfare State europeu, entre os anos de 1950 e início dos anos de 1970. Klaus Dörre (2006) é outro sociólogo alemão contemporâneo que também se ocupou do tema, procurando relacionar precariedade, integração social e subjetividade como base para a construção social da condição daqueles que ele denominou como "descartáveis".

Outra obra incisiva nesta direção é a do economista britânico Guy Standing (2014). Ele tem sido recentemente um dos autores de maior destaque na definição da formação de um precariado global. Para ele, ganha forma atualmente uma estrutura de classes profundamente diferente daquelas que predominaram em períodos anteriores do capitalismo. Nesta, surge uma nova classe, o precariado, que se caracteriza especialmente pela incerteza e insegurança crônicas. Para Standing, o capitalismo industrial nacional se propôs a habituar o núcleo do proletariado a um trabalho e a uma vida de estabilidade, enquanto o capital global atual pretende habituar o precariado a um trabalho e a uma vida de instabilidade. Em sua definição, "o precariado" hoje seria a classe situada logo abaixo do velho proletariado, coincidindo com a definição dos "sobrantes" de Robert Castel (2011) e dos trabalhadores precários na "zona cinzenta" da qual fala Ulrich Beck (1999). O precariado, para Standing, seria a classe "perigosa", por causa de sua desvinculação com a estrutura econômica e psicológica do capitalismo contemporâneo, sendo esta exatamente a razão que a permitiria tornar-se uma "classe para si" (Standing, 2014).

No Brasil, atualmente, a obra de Ruy Braga ganha visibilidade com sua tentativa de tematização do processo histórico de formação do que seria o nosso precariado. Como ponto de partida, realiza uma crítica das obras de Castel e Standing, e passa 
a definir o precariado como o "proletariado precarizado", ou seja, uma parte precarizada do proletariado (Braga, 2012). Para ele, sua definição seria mais precisa do que as de Castel e Standing, basicamente, por três razões. Primeiro, ela permitiria localizar o precariado no coração do próprio modo de produção capitalista e não meramente como subproduto da crise do desenvolvimento fordista. Em segundo lugar, enfatizaria a dimensão histórica e relacional do precariado como parte integrante da classe trabalhadora, e não simplesmente como um amálgama intergeracional e policlassista que assumiria de maneira progressiva a aparência de uma nova classe. Por fim, segundo Braga, sua definição de precariado, em vez de retirar arbitrariamente a condição de insegurança diretamente da relação salarial, possibilita tratar a precariedade como dimensão intrínseca ao processo de mercantilização do trabalho (Braga, 2012).

Ao voltar um pouco no tempo, a obra de André Gorz, desde os anos de 1980, a partir de seu clássico Adeus ao proletariado (Gorz, 1980), é um divisor de águas na interpretação sobre as sociedades do trabalho e das classes. Para Gorz, o capitalismo entra em profunda crise no período posterior à Segunda Guerra Mundial, considerando que o desenvolvimento das contradições de classe não acompanhou o desenvolvimento das forças produtivas. O fracasso da classe trabalhadora europeia, enquanto movimento social, seria o principal elemento empírico que confirmaria, segundo ele, um erro teórico de Marx, ou seja, o de que o proletariado poderia e deveria se tornar uma classe para si.

Este desdobramento imprevisível da história do capitalismo leva Gorz (2005) a declarar que "teríamos saído de uma sociedade do trabalho sem colocar nada em seu lugar". A ruptura histórica da simbiose entre trabalho e classe, nesta direção, essencial para se compreender a precariedade contemporânea, faz com que o autor procure uma definição alternativa à ideia de sociedade do trabalho, o que o leva ao desenvolvimento de uma teoria sobre a "sociedade do conhecimento" , ou do "imaterial", como ele definiria posteriormente (Gorz, 2004; 2005; Silva, 2008). Nesta nova sociedade, que começaria a se desdobrar a partir da crise estrutural do capitalismo após a Segunda Guerra, o conhecimento científico, especializado e tecnológico se torna a principal força produtiva, no lugar do trabalho. A crise estrutural do capitalismo industrial, nesta direção, significa a não convergência entre o desdobramento das forças produtivas e o correspondente desdobramento das contradições de classe que viriam a superar o sistema industrial burguês. Em resumo, ao invés de fomentar a autossuperação da lógica autodestrutiva do capital, o sistema global do capital aniquilou, fragmentou e cooptou a classe trabalhadora (Gorz, 2004). Esta análise servirá de base para sua incisiva afirmação de que agora, no período pós-fordista, "somos todos precários" (Gorz, 2004)¹.

\footnotetext{
1. Aqui, vale ressaltar que, o que a teoria social, depois de 1945, compreendeu como trabalho não corresponde exatamente às várias noções de trabalho encontradas na obra de Marx, e isso especialmente pensando na obra de Gorz, mesmo porque a realidade presenciada neste novo contexto é totalmente diferente daquela vivenciada por Marx. Especialmente a obra de Gorz não ignora a relação entre trabalho e produção de valor, mas procura atualizá-la diante do novo paradigma do conhecimento. Isso é nítido e central em todos os livros de sua fase madura.
} 
Essas mudanças empíricas - visíveis principalmente na história da classe trabalhadora europeia - criam o contexto para o conhecido questionamento de Claus Offe (1994), sobre se o trabalho ainda seria uma categoria sociológica-chave. Para ele, o crescimento do setor de serviços operou duas mudanças estruturais no capitalismo industrial: ele fragmenta o mercado de trabalho em atividades produtivas e informais, de um lado, e, consequentemente, fragmenta e hierarquiza internamente a classe trabalhadora. Neste aspecto, sua interpretação é semelhante à de André Gorz, ao perceber o enfraquecimento do proletariado e a perda paulatina e gradativa de sua simbiose com o trabalho enquanto atividade humana fundamental. Esta ruptura estrutural e existencial entre mercado de trabalho e classe trabalhadora faz com que o autor passe a apostar no "mundo da vida" como fonte de sentido, em lugar da "esfera do trabalho" (Offe, 1994).

Ulrich Beck também se posicionou contrário ao paradigma clássico da sociedade do trabalho e das classes. Enquanto Gorz e Offe sustentam argumentos específicos para a desconstrução de uma ideia de sociedade do trabalho, Beck apresenta uma perspectiva mais específica sobre a perda de validade do conceito de classe, que para ele se torna, no contexto dos anos de 1980, um conceito "zumbi", meramente descritivo (Beck, 1984). As perspectivas dos três autores se complementam e apresentam como ponto central comum o fato de construírem teoricamente o fim da sociedade do trabalho e das classes. Para Ulrich Beck, o individualismo, derivado da fragmentação crescente do trabalho formal e assalariado e do enfraquecimento dos laços familiares seria um conceito muito mais apropriado do que o de classe, para se compreender o período atual do capitalismo, que ele nomeia como "modernidade reflexiva" (Beck, 1984). Desta forma os três autores, em conjunto, representam uma perspectiva de interpretação da modernidade e do capitalismo que poderíamos definir como "pós-materialista".

Neste artigo, pretendo pavimentar, através de uma revisão bibliográfica, um caminho de rearticulação entre os conceitos de trabalho e de classe, que foram desarticulados pelo pensamento pós-materialista, de modo a explorar uma hipótese central: a relação teórica entre trabalho e classe, bem como sua correspondente realidade empírica, pode ser definida atualmente através de um processo de "generalização da precariedade", tanto no centro como na periferia do capitalismo. Compreendo como precariedade o fenômeno contemporâneo de padecimento das condições e das relações de trabalho. Este exercício não precisa se restringir a um retorno direto aos clássicos fundadores da sociologia. O pensamento pós-materialista sobre o trabalho e as classes sociais colocou questões cruciais ao pensamento sociológico clássico, questões estas que não puderam ser vistas em sua totalidade por Marx ou por qualquer outro grande teórico da modernidade clássica. 
Desta maneira, uma reconstrução teórica que rearticule os conceitos de trabalho e classe - enquanto indissociáveis e centrais para qualquer teoria crítica do capitalismo e da modernidade contemporânea - precisa enfrentar algumas questões centrais, referentes a mudanças empíricas do capitalismo contemporâneo, e procurarei apresentá-la na sequência. Desta maneira, talvez seja possível a reconstrução de uma ideia atualizada de sociedade do trabalho e das classes, como sinônimo de capitalismo e modernidade, não desconsiderando o que ainda há de válido na contribuição dos clássicos da sociologia, mas também articulando o que há de novo em uma perspectiva teórica contemporânea.

Nesta direção, o primeiro aspecto que precisa ser considerado trata da condição de globalidade alcançada atualmente pela sociedade do trabalho e das classes. É o que explorarei na próxima seção. Na sequência, discutirei como o conhecimento especializado, científico e tecnológico se torna ao mesmo tempo uma nova força produtiva central e uma ideologia do capitalismo contemporâneo. Em seguida, procuro mostrar como a relação entre trabalho e classe conforma uma questão social central hoje e porque ela precisa ser tematizada. Por fim, busco uma síntese de como se estrutura atualmente o fenômeno da generalização da precariedade.

\section{A globalidade da sociedade do trabalho e das classes}

O primeiro aspecto essencial para se pensar em reconciliação entre os conceitos de trabalho e classe, bem como de suas correspondentes realidades empíricas, após o seu divórcio realizado pelo pós-materialismo, é pensar a dimensão atual da sociedade do trabalho e das classes em sua globalidade. Este aspecto da realidade atual é fundamental para a compreensão da produção global da precariedade. Nesta tentativa, deparamo-nos com uma diferença fundamental entre a perspectiva clássica e a perspectiva contemporânea. Para os clássicos da sociologia, a sociedade do trabalho e das classes era sinônimo de sociedade burguesa e nacional. Minha perspectiva nesta direção é que o enfoque nas histórias nacionais, o que significa em grande medida a história dos Estados nacionais e de seus correspondentes mitos nacionais, se torna hoje mais difícil de sustentar teórica e empiricamente. Para Guy Standing (2014), a estruturação de uma sociedade global das classes pode ser vista na própria condição global do precariado.

Nesta direção, um primeiro dado empírico inegável é a globalização da economia. Há uma vasta literatura sobre o tema como, por exemplo, as obras de Ulrich Beck e, no Brasil, Paul Singer e Otávio lanni (Beck, 1997; Singer, 1998; Ianni, 1994). Para este último, em sua obra tardia e pouco difundida, a globalização deveria ser 
o novo paradigma das ciências sociais. Em grande medida ele estava certo, pois critérios objetivos de análise, como a internacionalização crescente da economia e das classes sociais, a formação de forças políticas e sociais supranacionais, bem como a padronização da produção do mercado em escala global, através da força crescente da tecnologia, são dados inegáveis. Entretanto, é preciso tematizar em que medida a ideia de globalização pode ser um conceito válido para uma teoria crítica da sociedade contemporânea e em que medida pode se tornar facilmente uma ideologia liberal de negação da validade normativa e da função política dos Estados nacionais.

No geral, os teóricos da globalização parecem concordar em alguns pontos essenciais:

1. a globalização da economia parece ser o principal aspecto essencial, em comparação com as outras dimensões da vida social;

2. a globalização aumenta a exclusão social nas dimensões nacionais e regionais-locais;

3. os Estados-nacionais perdem força relativa diante do capital financeiro e de novos agentes políticos e sociais internacionais, articulados ao mundo da vida, como as organizações não governamentais.

Não podemos negar que a globalização se coloca como paradigma que precisa ser enfrentado e criticado. Na prática, o conceito se remete à atual fase do capitalismo financeiro, na qual as forças produtivas desenvolveram e especializaram sua condição de internacionalização e de padronização dos critérios de produção.

Um observador atento do mundo corporativo contemporâneo, por exemplo, poderia confirmar que não há diferença essencial entre as formas de organização produtiva e os valores que as legitimam nos Estados Unidos, na Europa, no Mundo Árabe ou na América Latina (Sennett, 2006; 2015). As diferenças encontradas por pesquisas estatísticas são muito mais de ordem quantitativa do que qualitativa. As diferenças encontram-se também muito mais nas tentativas dominantes de definição da realidade do que na realidade empírica propriamente dita. No geral, podemos dizer que a forma de organização produtiva que se universalizou no capitalismo - e por isso mesmo é dominante - é aquela que André Gorz (2004) define como "pós-fordismo", ou seja, uma produção induzida que calcula exatamente o que vai produzir a partir de pesquisas encomendadas sobre as demandas específicas de cada setor do mercado. No Brasil, Ruy Braga (2012) chama de pós-fordismo financeirizado o período atual, que substitui o nosso fordismo periférico e cria um novo contexto de transformação de parte do proletariado em precariado. 
Na dimensão dos valores, o princípio da "flexibilidade", como tematizado por Richard Sennett (2006), Luc Boltanski e Ève Chiapello (2006), impõe-se de duas formas: primeiro, nas relações interpessoais dentro do mundo corporativo; segundo, na flexibilidade do caráter e da subjetividade, no mundo da vida, como consequência. Esta realidade é universal e pode ser constatada em estudos empíricos sobre o "mundo do trabalho" tanto na Europa como no Brasil (Vester, 2007; Antunes, 2000; Ramalho \& Santana, 2006). Nesta direção, David Harvey (1992) procurou compreender a relação entre a ascensão de formas culturais que ele define como pós-modernas e a emergência de modos mais flexíveis de acumulação do capital, bem como de um novo ciclo de compressão do tempo e do espaço na organização do capitalismo.

A realidade do mundo corporativo e seus efeitos normativos na sociedade como um todo hoje é globalizada, de modo que a tentativa de articulação contemporânea entre os conceitos de trabalho e classe não deve desconsiderá-la. Isso nos remete à necessidade de questionamento sobre a relação teórica dominante no século XX entre as ideias de sociedades nacionais e sociedades do trabalho e da classe, o que não deve naturalmente desconsiderar que as sociedades nacionais ainda existem, sob o regimento de seus respectivos Estados - mesmo se com certa força em decadência - e de seus respectivos mitos nacionais. A questão mais importante neste sentido é que as sociedades nacionais não podem mais ser a principal unidade analítica de explicação do capitalismo contemporâneo.

Nesta direção, a crítica de Ulrich Beck (2008) ao que ele define como "nacionalismo metodológico" parece bastante valiosa. O que se apresenta como fundamental em sua crítica é sua percepção de que quase toda a sociologia sobre a desigualdade dominante no século XX é direcionada por categorias políticas e cognitivas das histórias nacionais. Neste sentido, a sociologia da desigualdade inclui as fragmentadas sociologias do trabalho e das classes, em suas variadas vertentes. A percepção do autor sugere que um reducionismo epistemológico e teórico dominou a sociologia da desigualdade durante um século. Uma das principais edições da realidade operadas pelo nacionalismo metodológico é que ele naturaliza as desigualdades sociais como se fossem desigualdades nacionais (Beck, 2008).

Naturalmente, é possível e necessário que se identifiquem as desigualdades sociais em sua dimensão histórico-nacional. Não é outra coisa o que orienta a construção sistemática de parâmetros para a elaboração de políticas sociais e para o seu implemento efetivo pelo Estado nacional. Entretanto, a questão mais fundamental que pode e deve ser levantada e perseguida é em que dimensão, principalmente, se produz a desigualdade social contemporânea. Nesta direção, a desigualdade social 
pode ser hipoteticamente considerada como sinônimo de desigualdade de classe, o que pressupõe lugares desiguais em uma hierarquia social e moral do trabalho.

As sociedades nacionais burguesas - cuja gênese histórica foi explicada por clássicos como Karl Marx (2007), Werner Sombart (1983) e Norbert Elias (1981) - apresentam algumas características essenciais que podem ser recuperadas na busca por uma resposta satisfatória para a questão colocada acima. Para defender o pressuposto de que a sociedade burguesa industrial era sinônimo de uma sociedade de classes, regida pelo trabalho, um bom caminho pode ser considerar qual é a mudança na hierarquia social que se encontra em sua gênese, ou seja, qual é a hierarquia social específica que a estrutura. Para teóricos como Elias (1981) e Sombart (1983), a ascensão da sociedade burguesa, em contrapartida à sociedade de corte, responde a boa parte desta pergunta. Para Marx (2007), o conflito de classes no qual o proletariado deveria adquirir um papel de protagonista também indica uma pista fundamental para se decifrar a questão. O aspecto essencial com o qual podemos aprender a partir da gênese das sociedades nacionais, para se pensar em uma sociedade do trabalho e das classes de dimensões globais atualmente, entretanto, é que só se define uma sociedade como algo novo e peculiar quando se tem clareza acerca da especificidade de sua hierarquia social.

Assim sendo, se quisermos definir a sociedade do trabalho e das classes contemporânea em sua dimensão global é preciso identificar nesta dimensão qual é a sua hierarquia social. Isto pressupõe que continuemos considerando esta sociedade como moderna em sua essência, e não como pós-moderna ou de qualquer outra natureza. Neste sentido, não deixamos de ser uma sociedade moderna enquanto sinônimo de sociedade de classes regida pelo trabalho, porém deixamos de ser um conjunto de sociedades nacionais divididas em continentes ou blocos centrais ou periféricos para adquirir uma dimensão de globalidade. Uma evidência fundamental desta condição de globalidade é a existência de uma estrutura de classes internacional, ou seja, a existência de uma hierarquia social que não mais se restringe às características das sociedades nacionais. A compreensão desta estrutura é fundamental para o entendimento da generalização da precariedade, como veremos ao final.

No topo da hierarquia social contemporânea encontra-se uma elite global, tematizada por vários autores contemporâneos, ainda que de forma fragmentada e problemática. Uma destas definições se encontra no livro Muitas globalizações, derivado de uma pesquisa internacional organizada por Samuel Huntington e Peter Berger (2004). Um dos principais resultados empíricos encontrados em todos os continentes foi a existência de uma elite global. Também Ulrich Beck (1997) - em seu livro específico sobre o tema, Was ist Globalisierung? - defende a existência de uma elite 
global, detentora do capital financeiro que organiza o mundo e de um poder político de influência e decisão que se impõe acima dos Estados nacionais.

Por fim, um consistente livro nesta direção é o de Richard Münch (2008) - intitulado Globale Elite, lokale Autoritäten -, no qual investiga com pesquisa empírica as mudanças nos padrões da bildung alemã hoje, como resultado da influência internacional de um padrão de ensino reducionista voltado exclusivamente para a inserção imediata no mercado. Ainda que sua definição de elite global seja problemática - ao identificar esta apenas como uma elite do conhecimento e ignorar a parte da elite global diretamente beneficiária do capital financeiro -, o que interessa destacar aqui é a existência empírica de uma elite supranacional com características econômicas e identitárias que nada tem a ver com o pertencimento a alguma sociedade nacional.

Outra evidência empírica da existência de uma estrutura de classes internacional é a identificação de uma classe média transnacional e cosmopolita. Como mostrou Jessé Souza (2006), a forma mais frágil e imprecisa de se identificar e definir uma classe social é a sua redução ao parâmetro da renda. Logo, a percepção da existência de uma classe média internacional hoje pode ser possível tanto pela observação de seu estilo de vida cosmopolita como pela renda. Qualquer observador atento pode notar, em qualquer megalópole global - seja no Brasil, na Europa ou no Oriente -, o expressivo volume de turistas que por ali circulam todos os dias do ano. Nas grandes cidades europeias, o trânsito constante de uma juventude, cuja língua comum é o inglês, praticamente a primeira língua desta classe média, acima dos idiomas nacionais, é outro dado empírico facilmente visto, só para tomar dois exemplos.

Por fim, o surgimento de uma nova classe trabalhadora, informalizada e precarizada pelo critério produtivo e normativo da flexibilidade do capitalismo financeiro, é identificável tanto no Brasil como na Índia ou na França. Independentemente das diferenças, evidentemente importantes, em termos de segurança e condições de trabalho, que em países como a Alemanha no geral ainda são melhores do que em países como o Brasil, a questão de fundo é que os critérios objetivos de flexibilização e precarização das condições e das relações de trabalho são os mesmos tanto no centro como na periferia do capitalismo (Sennett, 2006; Vester, 2007; Antunes, 2000; Ramalho \& Santana, 2006). Também as imigrações de trabalhadores em todo o mundo - sejam estas de toda a América Latina para o Brasil, ou do Leste Europeu para países como Alemanha e França, bem como a constante imigração para os Estados Unidos - mostram que frações tanto tradicionais quanto novas da classe trabalhadora não necessariamente pertencem a territórios e a identidades nacionais, mesmo que suas possibilidades de circulação sejam bem mais restritas e precárias do que aquelas vivenciadas pela classe média e pela elite. 
Deste modo, a identificação de uma hierarquia social e de uma estrutura de classes internacional é um aspecto decisivo para se pensar na dimensão global da sociedade de classes e do trabalho, bem como em sua precariedade. Outro aspecto necessário para esta reconstrução teórica depende da articulação das características inerentes a cada classe com as formas de trabalho essenciais que elas exercem. No caso da elite global, trata-se de uma classe que não trabalha - se tomarmos aqui o sentido humano do trabalho em Marx -, mas vive da herança ou dos rendimentos de volumosos patrimônios materiais e imateriais, administrados pelo serviço de consultores muito bem pagos (outra elite: a do conhecimento, sendo esta a fração abaixo da elite global).

No caso da classe média, esta ainda se divide entre as tradicionais profissões liberais e a crescente atividade de consultorias, nas quais vendem seus nomes e títulos simbolicamente. Quanto à classe trabalhadora, esta se divide entre ocupações por vínculos tradicionais do sistema industrial, também globalizado em sua lógica produtiva e em sua legitimação, e, por outro lado, no cada vez mais crescente mercado de trabalho precário e informalizado. No caso da "ralé", estrutural na periferia (Souza, 2009) e agora crescente no centro, sua relação com o trabalho é negativa, pois ela é a classe impossibilitada socialmente de exercer qualquer trabalho considerado produtivo e digno em qualquer lugar do mundo.

Deste modo, podemos perceber a existência de uma estrutura de classes internacional, bem como a relação diferencial de cada classe com a categoria empírica do trabalho, percepção esta fundamental para a teorização crítica de uma sociedade globalizada e precarizada, na qual trabalho e classe são categorias teóricas e empíricas indissociáveis. Na próxima seção, investigaremos a segunda característica fundamental desta sociedade, ou seja, em que medida a tecnologia e o conhecimento especializado são de fato uma força produtiva estruturante do capitalismo contemporâneo e em que medida podem se tornar uma ideologia legitimadora de sua reprodução e da consequente radicalização de sua desigualdade de classe.

\section{A ambiguidade da}

\section{"sociedade do conhecimento"}

A importância do conhecimento para a organização da produção capitalista, bem como o significado de seu intermédio nas relações de produção, já era um tema importante na obra de Marx. No pensamento contemporâneo pós-materialista, no entanto, existe uma alteração fundamental na relação teórica entre conhecimento, trabalho e classes sociais. O conhecimento, enquanto conceito e realidade empírica, passa a competir com o trabalho na função de principal categoria analítica das 
sociedades contemporâneas. Na teoria marxista, o conhecimento é apenas uma categoria dentre outras, subjugada a centralidade do trabalho enquanto elemento essencial da ação humana. No pensamento pós-materialista, o conhecimento alcança o status de categoria central.

Para André Gorz (1980) - um dos principais teóricos da sociedade do conhecimento, a partir da publicação de seu livro Adeus ao proletariado - o conhecimento se torna a principal força produtiva do capitalismo contemporâneo, que deixa de ser uma sociedade industrial e passa a ser uma sociedade "imaterial" (Gorz, 2004; 2005). Dois dados históricos autorizam Gorz a declarar a sociedade do trabalho no sentido marxista como esgotada em si mesma. O primeiro é a própria crise estrutural do capitalismo, na qual a automação não consegue cumprir sua promessa de autossuperação sistêmica e geração de empregos. Como consequência e articulado a este fenômeno o autor se remete ao fracasso do proletariado em cumprir com sua função histórica delineada por Marx, ou seja, desenvolver sua força ontológica e agir como protagonista na superação do sistema.

A obra de Gorz é ambígua e produtiva para os objetivos da reconstrução teórica deste debate. Sua análise do pós-fordismo é uma das mais brilhantes sobre a compreensão do processo histórico de transição de um capitalismo nacional e europeu - simbolizado pelo mito do welfare State - para um capitalismo globalizado e precarizado em suas bases mais profundas, tanto em termos de seu funcionamento prático, quanto na dimensão de seus valores e de sua legitimação. Esta análise tardia de Gorz (2004) se completa com suas intuições anteriores, ainda na década de 1980, sobre a perda de sentido histórico da classe trabalhadora (em termos empíricos e, principalmente, europeus). A ruína do capitalismo clássico coincide com a própria ruína da classe trabalhadora, agora mais precarizada e dominada pelo capital, impossibilitada de qualquer organização social e tomada de consciência, apartada de qualquer possibilidade de reencontro com sua subjetividade. Esta mudança nos rumos do capitalismo seria, para o autor, empiricamente suficiente para a descaracterização da ideia de sociedade do trabalho e o desenvolvimento da ideia de sociedade do conhecimento.

Entretanto, existe algo bastante problemático nesta perspectiva, em sua própria base filosófica mais profunda. O abandono de Marx e de sua sociedade do trabalho (e das classes, como sinônimos) só é possível se aceitamos a definição de sociedade do trabalho de Marx como a única possível. Logo, quando o seu esquema teórico não mais encontra fundamentos empíricos e correspondência histórica, a única saída é o abandono imediato da ideia de sociedade do trabalho. Entretanto, a questão não é tão simples. O argumento da sociedade do conhecimento, em Gorz, bem 
2. Uma leitura atenta das obras de Sennett, Boltanski e Chiapello, sobre o capitalismo atual reforça esta percepção. como a ideia de fim da centralidade do trabalho, em Claus Offe, e a substituição do paradigma da classe pelo do individualismo de Ulrich Beck colocam questões fundamentais que vão direto ao cerne da teoria marxista.

No caso de Gorz, a questão central mais importante nesta direção é que a revolução tecnológica altera radicalmente a capacidade de produção e de dominação do capitalismo. O aspecto crítico nesta direção é que o capital se especializou em sua função de dominação, minando as forças organizativas da classe trabalhadora de forma ainda mais sutil e impessoal do que no fordismo ${ }^{2}$. Esta mudança no "topo" do capitalismo, onde entra o conhecimento científico, tecnológico e especializado como "produtor da produção", pode ser um elemento teórico fundamental para uma reconstrução crítica de uma teoria do capitalismo contemporâneo. O conhecimento tecnológico e especializado permite, no topo do mundo corporativo por exemplo, uma administração mais enxuta, pragmática e direcionada, enquanto, nas suas bases, opera uma seletividade ainda mais precisa e radical, atuando como o principal critério meritocrático, sob o signo cada vez mais vago e ambíguo da "qualificação", que se apresenta como individual, mas é sempre social, definida desde o ponto de partida da origem de classe.

Um aspecto essencial da transição do capitalismo nacional fordista para o pós-fordismo pode ser visto através do crescimento do setor de serviços. Em boa medida, ele é a informalização do capitalismo, sua reorganização e reestruturação. A análise de Gorz neste sentido também é fundamental, ao mostrar como o pós-fordismo se desdobra através de um processo de "terceirização em cascata", no qual os trabalhadores mais qualificados permanecem nas "empresas mães", enquanto aqueles que não acompanham os novos altos níveis de qualificação vão para o setor de serviços, flexibilizados em seus contratos e na proteção salarial e seguridade social do trabalhador (Gorz, 2004). A lógica do sistema é intrinsecamente excludente, pois, ainda que todos os trabalhadores se qualifiquem da mesma maneira, não será possível a inserção de todos nos melhores postos, o que desmente o mito da meritocracia. A análise de Claus Offe (1994) também é importante nesta direção, ao mostrar como o setor de serviços é ao mesmo tempo uma fragmentação (ou seja, precarização) do mercado e da classe trabalhadora.

A qualidade destas análises poderia muito bem ter levado os autores a uma reconstrução crítica da ideia de sociedade do trabalho e das classes, mas não é o que acontece. Por isso, seria possível e necessário usar este "pós-materialismo" para contribuir a um objetivo contrário ao proposto, ou seja, a reconstrução do casamento entre trabalho e classe, sendo o conhecimento compreendido como novo media- 
dor precarizante desta relação. Assim, um primeiro aspecto a ser considerado é que o pós-materialismo de autores como Gorz, Offe e Beck apresenta uma perspectiva em parte crítica. No caso de Gorz, compreendemos que o conhecimento altera profundamente a capacidade de organização da produção, ou seja, o advento de um sistema do capital mais perfeito e desenvolvido em suas formas de dominação, o que só é possível com a revolução tecnológica.

A grande lacuna nesta direção - como também pode ser visto em toda a obra de Offe e Beck - é a ausência completa de tematização e definição de uma hierarquia social precisa, histórica, típica do novo capitalismo em questão. Naturalmente, esta lacuna escapa aos interesses teóricos e político-ideológicos destes autores, uma vez que a definição teórica e empírica crítica de uma hierarquia social só é possível se voltarmos à questão mais fundamental, ou seja, ao fato de que capitalismo é sinônimo de sociedade do trabalho e de classes, ou, de outra maneira, de uma sociedade de classes regida, estruturada e significada pelo trabalho enquanto categoria histórica e humana fundamental.

O pós-materialismo nesta direção abandona em sua essência a ideia de sociedade de classes e do trabalho, o que objetivamente o impede de perceber a hierarquia social de classes específica do capitalismo globalizado. Entretanto, sua análise da força do conhecimento, se não for transformada em ideologia, bem como sua percepção do que significa em termos concretos o setor de serviços, podem ser aliados importantes de uma nova teoria crítica do capitalismo contemporâneo.

Neste sentido, uma reconstrução crítica e histórica da relação teórica e empírica entre trabalho e classe, na dimensão do capitalismo globalizado, deve realizar uma síntese entre a tradição dos clássicos e o pós-materialismo. Da primeira, o aspecto essencial do qual uma teoria crítica não pode abrir mão é a consideração do capitalismo como sinônimo de sociedade do trabalho e das classes. Da segunda, as interpretações acerca do papel do conhecimento nas sociedades modernas, do advento do setor de serviços e da radicalização do individualismo. Uma contribuição decisiva para uma teorização acerca da relação contemporânea entre trabalho e classe, evitando-se ainda uma perspectiva ideológica.

No caso do conhecimento, a grande ideologia a ser evitada é a que reconhece ser ele um elemento democratizante das sociedades contemporâneas, no sentido de ampliar o acesso das classes populares ao trabalho digno, na hierarquia social do trabalho. Na análise de Gorz (2004), há uma importante distinção entre "conhecimento" e "saber", sendo o primeiro o conhecimento especializado e o segundo todo o saber mais profundo da humanidade, não científico e não tecnológico. Esta 
distinção é importante para pensarmos a relação diferencial entre os tipos de conhecimento e as diferentes classes sociais hoje.

Desta maneira, a relação objetiva entre conhecimento, trabalho e classes sociais, no capitalismo globalizado, apresenta-se com a valorização do conhecimento especializado agindo como fator estrutural que amplia a distância entre origem social de classe e inserção qualificada e digna no mercado de trabalho. Em contrapartida, o saber popular é desvalorizado, o que dificulta a ascensão social de pessoas das classes populares, algo que a ideologia do mérito e da qualificação, articulada à ideologia da democratização do ensino e da tecnologia, sistematicamente esconde. Com isso, a ideia de sociedade do conhecimento, válida por perceber a importância da força da tecnologia como fator precarizante de condições e de relações de trabalho apresenta-se como uma meia verdade da sociedade do trabalho contemporânea, na medida em que se transformou rapidamente na ideologia da democratização do acesso das classes populares a lugares privilegiados na hierarquia social do trabalho.

Vimos, até agora, dois aspectos essenciais da nova sociedade do trabalho e das classes:

1. a globalidade de sua reprodução e de sua hierarquia social; e

2. a função precarizante do conhecimento especializado e tecnológico em sua produção.

Vejamos, agora, um terceiro aspecto fundamental desta sociedade:

3. como e por que ela apresenta uma questão social central que precisa ser identificada e como esta adquire uma condição de globalidade.

\section{A nova questão social global}

A tentativa de rearticulação teórica entre os conceitos de trabalho e classe, bem como de suas correspondentes realidades empíricas, não pode se furtar do desafio de considerar a existência de uma questão social contemporânea que adquire dimensões de globalidade. Neste aspecto, a obra de Robert Castel (1998) é incisiva. Para ele, uma "questão social" pode ser definida como um problema essencial, a partir do qual uma sociedade se questiona sobre seus fundamentos e seu sentido mais profundo, sobre sua coesão social ou sobre sua desintegração. Se aceitarmos a hipótese de que vivemos em uma sociedade do trabalho e das classes sociais que hoje é globalizada, como vimos nos tópicos anteriores, precisamos então nos 
perguntar qual é a sua questão social, que nos mostra quais são os seus dilemas e o seu significado.

Nesta direção, a hipótese que gostaria de explorar agora é que a principal questão social da sociedade do trabalho e das classes em sua dimensão global é a generalização, inédita na história, da precarização das condições e das relações de trabalho, tanto no centro como na periferia do capitalismo. Naturalmente, a identificação de uma questão social global não deve negar as questões sociais em outras dimensões da realidade contemporânea, dentre as quais a dimensão das sociedades nacionais, que ainda existem. Se, por exemplo, considerarmos outro recorte metodológico, as diferenças históricas entre o centro e a periferia do capitalismo não podem ser desconsideradas, a questão da desigualdade social relacionada à segurança pública sempre foi mais importante em países periféricos como Brasil e México do que em países como Inglaterra ou Alemanha.

Ainda que haja mais de uma questão social relevante, o que está em jogo aqui, ao se identificar uma questão social importante, no sentido de Castel, é compreender que só se percebe e, consequentemente, se explica o sentido mais profundo de uma sociedade quando se identifica os seus problemas centrais, do qual depende toda a mudança social. Nessa direção, o importante livro de Robert Castel (1998) - As metamorfoses da questão social: uma crônica do salário - apresenta uma incisiva análise crítica sobre a mudança estrutural pela qual passa o capitalismo contemporâneo. Castel identifica, no caso europeu francês - um caso clássico da modernidade "central" - qual é a principal questão social que explica a "grande transformação", como em Karl Polanyi, da sociedade do trabalho e das classes atual. Sua análise do caso francês é fundamental para os objetivos de uma reconstrução crítica entre os conceitos de trabalho e classe, uma vez que aponta aspectos essenciais de uma mudança estrutural que hoje é universal e não apenas francesa ou brasileira. O ponto mais importante que deve ser ressaltado nesta direção é que hoje podemos identificar aspectos essenciais da mudança capitalista que podem ser vistos tanto em um caso da modernidade central como no caso da modernidade periférica brasileira.

Para Castel, a singularidade do fenômeno - que ele define como "desfiliação social" - seria a principal marca da sociedade francesa atual. Com este conceito, o autor procura definir um fenômeno novo que hoje é o maior indício do fracasso do capitalismo em todo o mundo: trata-se do processo sistemático e institucionalizado da produção de "sobrantes", ou seja, um número crescente de pessoas sadias e aptas para trabalhar que não encontram lugar no mercado produtivo ou que são expulsas deste sem nenhuma possibilidade de retorno (Castel, 1998). Para tanto, desenvolve uma análise sobre a fase do capitalismo geralmente definida como so- 
ciedade industrial, que ele prefere definir como "sociedade salarial", uma vez que a institucionalização do trabalho com vínculos fixos e com seguridade social encontra no salário o elo de ligação entre todos os indivíduos e a sociedade e assim se apresenta como o seu fundamento ontológico mais profundo.

Nesta direção, Castel percebe uma diferença essencial entre o capitalismo comercial e a sociedade salarial. No primeiro, já existiam os sobrantes, ou seja, os "vagabundos", mendigos e errantes, que não apresentavam condições físicas e sociais para se enquadrar no que na época era considerado como trabalho digno e produtivo como, por exemplo, as corporações de artesãos reconhecidas pelo Estado como realizadoras de trabalho (Castel, 1998). Entretanto, estes sobrantes "pré-modernos" não eram considerados pela sociedade como o outro negativo do trabalho, o que significa que vagabundo e mendigo não eram sinônimos de desempregado, preguiçoso e derrotado no mercado de trabalho, como percebemos hoje.

A construção social do estigma do vagabundo, como alguém que não trabalha simplesmente por que não quer trabalhar, é um produto, neste sentido, específico da sociedade salarial. Esta construção só é possível na medida em que a sociedade salarial (dominante no século XX europeu e cujo ápice histórico é o welfare State) define, sistematicamente, com toda a clareza, legitimada por suas principais instituições, a começar por Estado e mercado, dois aspectos essenciais desta sociedade: o que é o trabalho digno e, ao mesmo tempo, o fato de que este é o principal elo para o pertencimento e o reconhecimento social. Nesta direção, trabalho digno é sinônimo de trabalho assalariado, uma vez que o salário é o signo concreto de reconhecimento do ser produtivo pelo Estado e pelo mercado, na medida em que oferece ao indivíduo objetivamente a possibilidade de se provar produtivo e merecedor da condição de consumidor.

Esta noção de indivíduo produtivo, ancorada institucionalmente, generaliza-se no século XX em todos os países do capitalismo industrial. É a partir dela que as histórias dos capitalismos nacionais vão operar sua própria "modernização seletiva" (Souza, 2000), através de um desencaixe entre os valores e a definição do ser produtivo das modernidades centrais e as condições históricas objetivas encontradas pela expansão capitalista em cada caso específico de modernidade periférica.

A perspectiva de Castel, sobre o caso contemporâneo da modernidade central, permite-nos perceber como o desencaixe entre o ideal de ser produtivo e as realidades empíricas das situações objetivas de trabalho (fundamental para a definição das conformações históricas de classe) é universal no capitalismo e não inerente a alguma história nacional específica. Isso nos conduz a um segundo passo fun- 
damental para uma reconstrução teórica sobre a realidade empírica do trabalho e das classes sociais no capitalismo contemporâneo: a hipótese sustentada nesta direção é que, enquanto a sociedade salarial (nacional e principalmente a europeia) apresenta como marca central a generalização do trabalho digno (estrutural no centro e incompleta na periferia), a principal marca do capitalismo globalizado é a generalização da precariedade (ainda que conjuntural no centro e estrutural na periferia).

A sustentação inicial desta hipótese precisa articular os três aspectos fundamentais da realidade social contemporânea, vistos acima, de modo a se efetuar um casamento crítico entre os conceitos de trabalho e classe e suas respectivas realidades empíricas:

1. o capitalismo globalizado possui uma hierarquia social do trabalho e uma estrutura de classes que transcende as dimensões nacionais de análise;

2. o conhecimento especializado e tecnológico, enquanto força produtiva central, opera uma reorganização e ressignificação da hierarquia social do trabalho e da estrutura de classes transnacional, sistematizando uma forma de exclusão e precarização social própria deste novo capitalismo;

3. o novo capitalismo globalizado, enquanto sinônimo de sociedade mundial do trabalho e das classes, tem como sua principal questão social a generalização da precariedade do trabalho (além da produção do desemprego, sempre inerente ao capitalismo) e, consequentemente, a radicalização da desigualdade de classe.

Isso é o que procuraremos articular agora no tópico final.

\section{A generalização da precariedade}

Dois dados contemporâneos - um sobre o centro, outro sobre a periferia -, quando articulados conformam a principal evidência da existência de um novo capitalismo globalizado, com uma hierarquia social do trabalho e uma estrutura de classes específica, diferente daquelas pertencentes às histórias nacionais: trata-se do advento sem precedentes do trabalho precário na Europa "lado a", ou seja, economias estabelecidas como Inglaterra, França e Alemanha, articulando a crise europeia e a crise da zona do Euro, de um lado; e a ascensão de uma suposta nova classe média em países da modernidade periférica, da qual os Brics parecem ser a principal 
3. Este texto foi escrito antes do impeachment de Dilma Rousseff e da aprovação da reforma trabalhista atualmente em curso no Brasil. No atual cenário de rápidas mudanças políticas e econômicas, já presenciamos o início de um processo de desestabilização conjuntural do trabalho no Brasil. representação, de outro. A articulação destes dois dados parece fundamental para a tematização da sociedade global atual. O primeiro passo nesta direção deve ser o questionamento acerca da condição de meias verdades destes dados, o que significa que eles são ao mesmo tempo uma redução da realidade social contemporânea e também pistas fundamentais para uma conciliação teórica entre trabalho e classe.

No caso da periferia, podemos tomar o Brasil como exemplo emblemático. Um dos principais debates recentes na academia brasileira é sobre a ascensão de uma suposta nova classe média e o seu significado para a sociedade brasileira contemporânea. Os livros de Bolívar Lamounier (2009) e Marcelo Néri (2012) apontam para o surgimento de uma nova classe média no Brasil. Em contrapartida, Márcio Pochmann (2012) e Jessé Souza (2010) percebem o novo fenômeno como uma nova classe trabalhadora.

A existência da nova classe e a sua importância para a interpretação do Brasil contemporâneo parece um fato inegável. Por um lado, a conformação desta nova classe, tendo a informalidade e a flexibilidade, bem como a posse de um saber popular como alguns de seus traços essenciais, que se explica, em grande medida, pela reorganização tecnológica do capitalismo financeiro. Isso é fundamental para a percepção de um fenômeno que pode ser definido como a "estabilização conjuntural do trabalho" na periferia do capitalismo contemporâneo ${ }^{3}$.

Nesta direção, a ascensão contingente da nova classe trabalhadora, informal, flexível e precarizada é um episódio novo na história da relação entre trabalho e classe no Brasil, cuja principal característica é a "precarização estrutural do trabalho", típica da formação histórica das modernidades periféricas. Desta maneira, o surgimento de uma nova classe trabalhadora na periferia, pós-fordista, não mais vinculada diretamente à indústria, é um dos principais signos da nova sociedade global do trabalho e das classes. Entretanto, o fenômeno já se tornou rapidamente um mito das sociedades periféricas; sua condição de meia verdade precisa ser criticada.

A dimensão mitológica do fenômeno da nova classe trabalhadora e da sociedade que a vivencia sugere que ela proporciona uma evolução social em sua totalidade e no combate de sua desigualdade. A meia verdade aqui reside no fato de que a ascensão desta nova classe é em parte uma forma de progresso e desenvolvimento, mas não uma evolução social da sociedade brasileira em sua totalidade, que ainda possui uma parte significativa de suas classes populares estagnada em sua condição de desfiliação social, ou seja, em sua condição estrutural de sobrantes do mercado de trabalho e de não participação nos privilégios, no consumo e no reconhecimento da sociedade de classes. 
No caso da modernidade central - como na Inglaterra, França ou Alemanha - o principal discurso contemporâneo que as define em grande parte envolve a suposta crise europeia. Neste caso também reside uma meia verdade que precisa ser articulada, de modo a se perceber a relação entre trabalho e classe na Europa hoje e o que ela tem a ver com uma nova hierarquia social do trabalho e uma nova estrutura de classes internacional. O discurso da crise europeia está diretamente relacionado ao contexto europeu pós-welfare State, ou seja, o fim do bem-estar social, no qual pleno emprego, segurança e seguridade social, bem como democracia plena, foi um ideal histórico (Castel, 1998). A principal característica deste novo contexto é o advento sem precedentes do trabalho precário na história europeia moderna, ou seja, o trabalho sem vínculos formais, sem seguridade social e segurança ontológica, bem como, articulado a isso, o simples aumento gradativo do número de desempregados e de beneficiários de assistência social.

Neste caso, a meia verdade reside no fato de que apenas alguns países como, Espanha e Grécia, são realmente prejudicados pela suposta crise econômica. Ademais, se considerarmos a qualidade de vida e os índices de segurança pública e de níveis de educação e saúde, bem como de qualidade de serviços e infraestrutura de países como Alemanha ou França, ainda hoje, podemos perceber que estes ainda são nitidamente melhores do que na América Latina como um todo. Deste modo, é preciso perceber que a suposta crise europeia não explica (ainda que possa contribuir nesta direção) o fenômeno da precarização conjuntural do trabalho na Europa. Este se explica muito mais através da condição de globalidade adquirida pela sociedade contemporânea, com a reorganização de sua hierarquia social através da revolução tecnológica, transformando o conhecimento científico, tecnológico e especializado em uma força produtiva central.

Resguardado o exagero do alarde apocalíptico de autores pós-materialistas como Beck (2007) e Offe (1994), acerca do ocaso da história europeia, o que parece restar de concreto é o fato de que a Europa vivencia hoje, e isso de forma diferenciada entre seus países, uma "precarização conjuntural do trabalho", que com o tempo pode se tornar estrutural, mas ainda não é o caso (Maciel, 2014). Esta precarização conjuntural significa que apenas uma pequena parcela da população europeia é afetada seriamente pelo desemprego e pelo trabalho precário, de modo que isso ainda não ameaça seriamente a coesão social destas sociedades. A precarização conjuntural - que pode sim conduzir a um futuro não muito promissor (daí o medo dos teóricos europeus e sua preocupação com o retorno de um Estado social) - é apenas um processo parcial na reprodução contemporânea destas sociedades e que pode ameaçar a generalização do trabalho digno, ou seja, a estabilização estrutural do trabalho, realizada pelas histórias nacionais da modernidade central. 
No geral, é preciso perceber como a precarização conjuntural contemporânea do centro do capitalismo se articula com a estabilização conjuntural na periferia, na conformação de uma nova sociedade global do trabalho e das classes. Nesta direção, a contribuição pós-materialista pode ser de grande valia, se resguardado o seu teor ideológico, como no caso da teoria da sociedade do conhecimento. O aspecto essencial que dela podemos retirar é a compreensão do fato de que a tecnologia permite hoje uma organização e uma padronização da produção em escala global, em um processo que pode ser denominado como de reestruturação tecnológica. De resto, a lógica do capitalismo financeiro só permite a uma elite global a acumulação de riquezas por um caminho diferente daquele das burguesias nacionais, exatamente pela posse de um conhecimento científico e tecnológico de alguns milieux de uma elite do conhecimento que trabalha para os grandes investidores. É neste sentido que a sociedade do trabalho e das classes é produzida em escala global e não mais sob a égide dos Estados nacionais e de seus respectivos mitos, ainda que estes possam exercer algum papel na reprodução de uma hierarquia social do trabalho e de uma estrutura de classes produzidas em escala global.

Por fim, esta nova produção global da desigualdade ainda apresenta outro aspecto, fundamental para a compreensão da generalização da precariedade. Na medida em que a nova organização tecnológica do sistema produtivo se especializa na produção de uma hierarquia social do trabalho e de uma estrutura de classes em escala global, ela tende a radicalizar as desigualdades sociais em todo o mundo. Nesta direção, é possível observar em países da periferia do capitalismo de hoje - como o Brasil - um novo fenômeno que poderíamos chamar de "dupla precarização do trabalho", ou seja, a radicalização da precarização estrutural produzida historicamente pelas sociedades nacionais, na medida em que o sistema mundial produz uma generalização da precariedade tanto no centro quanto na periferia.

Esta afirmação tende a se confirmar na medida em que observamos que o fenômeno da estabilização conjuntural do trabalho, ou seja, a ascensão de uma nova classe trabalhadora em países da periferia como o Brasil, significa uma mudança social apenas para uma parte da sociedade, deixando ainda excluída uma boa parte das classes populares. A despeito de todas as celebrações acerca dos "emergentes", nossa classe de excluídos se encontra duplamente precarizada, primeiro historicamente, sendo desde sempre o sobrante da modernização seletiva na periferia; e agora também conjunturalmente, na medida em que os novos critérios de avaliação do ser produtivo, orientados pelo princípio da flexibilidade do capitalismo financeiro e pelas novas exigências de qualificação e de aquisição do conhecimento formal e especializado, aumentam ainda mais a distância entre as condições existenciais desta classe e as possibilidades objetivas de alcance de lugares dignos e privilegiados na hierarquia social do trabalho. 
Esta dupla precarização da classe de excluídos na periferia, adicionada ao seu surgimento crescente também no centro do capitalismo, é o que caracteriza o que nós podemos chamar de uma "generalização da precariedade", sendo esta a principal característica estrutural e normativa da sociedade do trabalho e das classes em sua dimensão global, contrariando empiricamente as meias verdades da sociedade do conhecimento, da crise europeia e dos emergentes da periferia. É nesta direção que uma reconstrução teórica acerca da relação contemporânea entre os conceitos de trabalho e classe, bem como de suas correspondentes realidades empíricas precisa avançar, de modo a contribuir para uma nova teoria crítica do capitalismo contemporâneo em sua totalidade.

\section{Referências}

ANTUNES, Ricardo. Adeus ao trabalho? Ensaio sobre as metamorfoses e a centralidade do mundo do trabalho. São Paulo: Cortez, 2000.

BECK, Ulrich. Die Neuvermessung der Ungleichheit unter den Menschen. Frankfurt am Main: Suhrkamp, 2008.

—. Schöne neue Arbeitswelt. Frankfurt am Main: Suhrkamp, 2007.

—. Was ist Globalisierung? Frankfurt am Main: Suhrkamp, 1997.

- Risikogesellschaft. Auf dem Weg in eine andere Moderne. Frankfurt am Main: Suhrkamp, 1986.

BERGER, Peter; HUNTINGTON, Samuel. Muitas globalizações. Diversidade cultural no mundo contemporâneo. Rio de Janeiro: Record, 2004.

BOLTANSKI, Luc; CHIAPELLO, Ève. The new spirit of capitalism. 2. ed. New York: Verso, 2005.

BRAGA, Ruy. A política do precariado. Do populismo à hegemonia lulista. São Paulo: Boitempo, 2012.

CASTEL, Robert. Die Krise der Arbeit. Neue Unsicherheiten und die Zukunft des Individuums. Hamburg: Hamburger Edition HIS, 2011.

- Metamorfoses da questão social. Uma crônica do salário. Petrópolis (RJ): Vozes, 1998.

DÖRRE, Klaus. Prekäre Arbeit. Unsichere Beschäftigungsverhältnisse und ihre sozialen Folgen. Arbeit, v. 1, n. 15, p. 181-193, 2006. 
DURKHEIM, Émile. Da divisão do trabalho social. São Paulo: Martins fontes, 2008.

ELIAS, Norbert. Über den Prozess der Zivilisation. Soziogenetische und psychogenetische Untersuchungen. Erster Band. Wandlungen des Verhaltens in den weltlichen Oberschichten des Abendlandes. Frankfurt am Main: Surhkamp, 1981.

GORZ, André. O imaterial. Conhecimento, valor e capital. São Paulo: Annablume, 2005.

—. Misérias do presente, riqueza do possível. São Paulo: Annablume, 2004.

—. Abschied vom Proletariat. Jenseits des Sozialismus. Frankfurt am Main: Europäische Verlagsanstalt, 1980.

HARVEY, David. Condição pós-moderna. Uma pesquisa sobre as origens da mudança cultural. São Paulo: Loyola, 1992.

IANNI, Octávio. Globalização: novo paradigma das ciências sociais. Estudos avançados, v. 8, n. 21, p. 147-163, Maio-Ago. 1994.

LAMOUNIER, Bolívar; SOUZA, Amaury. A classe média brasileira. Ambições, valores e projetos de sociedade. São Paulo: Campus, 2009.

MACIEL, Fabrício. A nova sociedade mundial do trabalho: para além de centro e periferia? São Paulo: Annablume, 2014.

MARX, Karl. A ideologia alemã. Rio de janeiro: Record, 2007.

MÜNCH, Richard. Globale Eliten, lokale Autoritaten. Frankfurt am Main: Suhrkamp, 2008.

NERI, Marcelo. A nova classe média. O lado brilhante da base da pirâmide. São Paulo: Saraiva, 2012.

OFFE, Claus. Capitalismo desorganizado. São Paulo: Brasiliense, 1994.

POCHMANN, Marcio. Nova classe média? O trabalho na pirâmide social brasileira. São Paulo: Boitempo, 2012.

RAMALHO, José Ricardo; SANTANA, Marco Aurélio. Flexibilidade à francesa. TrabaIhadores na Peugeot Citröen brasileira. Tempo Social, Revista de Sociologia da USP, v. 18, n 1, p. $115-132,2006$

SENNETT, Richard. A cultura do novo capitalismo. Rio de Janeiro; São Paulo: Record, 2015. 
—. A corrosão do caráter. Rio de Janeiro: Record, 2006.

SILVA, Josué Pereira da. Trabalho, cidadania e reconhecimento. São Paulo: Annablume, 2008.

—. André Gorz: trabalho e política. São Paulo: Annablume, 2002.

SIMMEL, Georg. Der Begriff und die Tragödie der Kultur. In: SIMMEL, Georg. Philosophische Kultur. Frankfurt am Main: Suhrkamp, 2006 [1911].

SINGER, Paul. Globalização e desemprego: diagnóstico e alternativas. São Paulo: Contexto, 1998.

SOMBART, Werner. Liebe, Luxus und Kapitalismus. Über die Entstehung der modernen Welt aus dem Geist der Verschwendung. Berlin: Verlag Klaus Wagenbach, 1983.

—. Die Ordnung des wirtschaftslebens. Berlin: Springer, 1927.

SOUZA, Jessé. Os batalhadores brasileiros. Nova classe média ou nova classe trabaIhadora? Belo Horizonte: Editora UFMG, 2010.

—. A ralé brasileira. Quem é e como vive. Belo Horizonte: Editora UFMG, 2009.

_. A invisibilidade da desigualdade brasileira. Belo Horizonte: Editora UFMG, 2006

—. A construção social da subcidadania. Belo Horizonte; Rio de janeiro: Editora UFMG; luperj, 2003.

A modernização seletiva. Brasília: Editora UnB, 2000.

STANDING, Guy. O precariado e a luta de classes. Revista Crítica de Ciências Sociais, n. 103, p. 9-24, Maio 2014.

VESTER, Michael; TEIWES-KÜGLER, Christel; LANGE-VESTER, Andrea. Die neuen Arbeitnehmer. Zunehmende Kompetenzen - wachsende Unsicherheit. Hamburg: VSA-Verlag, 2007.

WEBER, Max. A ética protestante e o espírito do capitalismo. São Paulo: Companhia das Letras, 2004. 
